\title{
Micromechanical framework for a 3D solid cohesion model - DEM implementation, validation and perspectives
}

\author{
Mohammad Sanayei*, Abbas Farhat ${ }^{\dagger}$, Li-Hua Luu ${ }^{\dagger}$, Lukas Werner ${ }^{\ddagger}$, Christoph Rettinger ${ }^{\ddagger}$, \\ Pierre Philippe ${ }^{\dagger}$ and Pablo Cuéllar* \\ ${ }^{*}$ Federal Institute for Materials Research and Testing (BAM), Division 7.2 for Buildings and \\ Structures, Berlin, Germany; e-mail: mohammad.sanayei@bam.de; http://www.bam.de/ \\ ${ }^{\dagger}$ RECOVER, INRAE Aix Marseille Univ, Aix-en-Provence, France \\ $¥$ Chair for System Simulation, Friedrich-Alexander-Universität Erlangen-Nürnberg, Cauerstraße 11, \\ 91058 Erlangen, Germany
}

\begin{abstract}
Natural soil deposits such as carbonate sands in the marine environment may show an effective cohesion due to intergranular solid bridges formed by calcareous precipitation. Such cementation effect endows the granular material with the ability to resist some degree of tensile stress in addition to the compressive and shearing resistance proper of uncemented frictional sands [1]. The tensile resistance of such materials may be quantified based on measures of debonding force at the micro-scale and using appropriate homogenization techniques [2]. However, it is still a challenge to assess the influence of solid intergranular cohesion on the mechanical behaviour of soils in many practical engineering problems (e.g. on the erodibility of soils $[3,4]$ or on the fluidization failure of geotechnical foundations [5]). Recent advances both in computational hardware and parallelization strategies make it nowadays possible to address such problems from a micromechanical perspective [6].

Here we introduce a simple model for solid cohesion and its implementation within a 3D discrete element framework. The model involves a classical viscoelastic bond rheology and specific debonding modes for tensile, shearing, bending and torsional solicitations. An implementation into the general computational framework of waLBerla [7] permits its integration in multi-physical simulations and the use of state-of-the-art HPC capabilities.
\end{abstract}

We finally present a calibration of the model to match experimental data from an artificial granular soil made out of cemented glass beads [2] and a validation of the approach with some macromechanical applications.

\section{REFERENCES}

[1] Collins, B.D. and Sitar, N., (2009). Geotechnical Properties of Cemented Sands in Steep Slopes. Journal of Geotechnical and Geoenvironmental Engineering, 135(10): 1359-1366.

[2] Farhat, A.; Luu, L.-H.; Philippe, P. and Cuéllar, P. (2021). Multi-scale cohesion force measurements for cemented granular materials. Proc. of Powders \& Grains 2021 (accepted)

[3] Brunier-Coulin, F.; Cuéllar, P. and Philippe, P. (2020). Generalized Shields criterion for weakly cohesive granular materials, Physical Review Fluids, 5(3), 034308.

[4] Philippe, P.; Benseghier, Z.; Brunier-Coulin, F.; Luu, L.-H.; Cuéllar, P. and Bonelli, S. (2021). Extending the Shields criterion to erosion of weakly cemented granular soils, Proc. of Powders \& Grains 2021 (accepted)

[5] Cuéllar, P.; Sanayei, M.; Farhat, A.; Luu, L.-H.; Doghmane, A.; Philippe, P.; Werner, L.; Rettinger, C. and Baeßler, M. (2021). On the role of solid cementation for localized fluidization problems in hydraulic earthworks and offshore foundations - Validating a micromechanical LBM-DEM approach. Proc. PARTICLES 2021 (submitted)

[6] Benseghier, Z.; Cuéllar, P.; Luu, L.-H.; Bonelli, S. and Philippe, P. (2020). A parallel GPU-based computational framework for the micromechanical analysis of geotechnical and erosion problems. Comput. Geotechn. 120, 103404

[7] Bauer, M.; Eibl, S.; Godenschwager, C.; Kohl, N.; Kuron, M.; Rettinger, C.; et al. (2020): WALBERLA: A block-structured high-performance framework for multiphysics simulations. Computers \& Mathematics with Applications 81: 478-501 